\title{
Letters
}

\section{Erectile dysfunction: NHS should meet current need before preventing future medical needs}

EDITOR-In 1998, coincident with a shift in treatment of erectile dysfunction from specialists to general practitioners, rationing of all drug treatments for impotence was introduced in the British NHS. ${ }^{1}$ In addition to rationing by selecting 12 causes of erectile dysfunction eligible for NHS treatment (and patients with "severe distress" confirmed by a psychiatrist), the Department of Health used data on the frequency of heterosexual sexual intercourse ${ }^{2}$ to recommend that one treatment a week was appropriate for most patients.

Daniels argues that the ethical value relevant to rationing is justice operationalised by referring treatment decisions to clinical need understood as the distance between patients' current health state and the "normal functioning range" for the human species." For impotence, the recommendation on how often treatment should be given was based on results of the first survey of self reported patterns of sexual behaviour in the UK population over a four week period. ${ }^{2}$

To examine the robustness of linkage between the Department of Health's recommendation and the survey data we dichotomised married or cohabiting men aged $20-59$ years $(n=4624)$ in the dataset into those whose sexual needs would or would not be met by one treatment per week. As patients presenting for treatment of erectile dysfunction aspire to be within a distribution of intercourse frequency that does not include zero, results were recalculated after removal of those reporting no sexual activity during the previous four weeks.

One treatment a week leaves a distance between the relevant population norm and that offered by the NHS: $44 \%$ of men aged 40-59 and 55\% aged 40-44 years have a pattern of sexual activity not met by the government's recommendation (table). In the interests of transparency and justice guidance

Self reported patterns of sexual activity in 4624 British men

\begin{tabular}{|c|c|c|c|c|}
\hline \multirow[b]{2}{*}{ Age group (years) } & \multicolumn{2}{|c|}{$\begin{array}{l}\text { Men with self reported activity greater } \\
\text { than once weekly }(n=4624)\end{array}$} & \multicolumn{2}{|c|}{$\begin{array}{l}\text { Men with self reported activity greater than } \\
\text { once weekly minus men with no sexual } \\
\text { activity over } 4 \text { week study period ( } n=4316 \text { ) }\end{array}$} \\
\hline & No (\%) & $95 \% \mathrm{Cl}$ & No (\%) & $95 \% \mathrm{Cl}$ \\
\hline $40-44$ & $742(51)$ & 48 to 55 & $687(55)$ & 52 to 59 \\
\hline $45-49$ & 545 (41) & 37 to 45 & $484(46)$ & 42 to 51 \\
\hline $50-54$ & $448(30)$ & 26 to 35 & $385(35)$ & 31 to 40 \\
\hline $55-59$ & $445(20)$ & 17 to 24 & 316 (28) & 24 to 34 \\
\hline $40-59$ & 2180 (38) & 36 to 40 & $1872(44)$ & 42 to 47 \\
\hline $20-39$ & 2444 (61) & 59 to 63 & 2321 (64) & 62 to 66 \\
\hline
\end{tabular}

Firstly, they do not compare like with like and ignore differing methods. Different instruments assess coping styles differently and may not be comparable. Thus conclusions cannot be drawn convincingly. Out of 28 studies, 13 had less than three years' follow up (shortest eight weeks). However, in relation to early breast cancer less than five years of follow up produces inconclusive results.

Secondly, our study was relegated to the realms of irrelevance by saying that the recent large UK study $(\mathrm{n}=578)$, while of higher quality, reported mixed findings: helplessness or hopelessness predicted recurrence when patients with high and low scores were compared but not when it was the predominant coping style. ${ }^{2}$ The main importance of our clearly stated findings concerning helplessness and hopelessness was missed. Mixed findings were not reported.

Although predominant coping style was arbitrarily defined, helplessness or hopelessness is robust across many studies. A high score on this subscale is a valid measure, reflecting a response amenable to psychological intervention. This finding was crucially important for encouraging adequate provision of psychological care in oncology, as was the small, cautiously interpreted tendency to poorer outcome found in severely depressed patients. Patient responsibility (or blame) is removed, and the onus shifts to the medical profession to identify and provide help for those at risk.

Dismissal of our study-which used rigorous methods, controlled for known prognostic variables, was sufficiently large, had a long follow up, and found a survival effect-does the research no service. Better to conclude that many poor studies fail to show any effect of coping response on survival, but high quality studies provide evidence suggesting that further good research is needed. Meanwhile the adverse effect on outcome of a helpless or hopeless coping response clearly argues for the provision of better psychological resources.

Maggie Watson consultant clinical psychologist Janis Davidson-Homewood research assistant Royal Marsden Hospital NHS Trust, Sutton, Surrey SM2 5PT

Jo Haviland statistician

Judith Bliss team leader

Institute of Cancer Research, Clinical Trials and

Statistics Unit, Sutton, Surrey SM2 5NG

1 Petticrew M, Bell R, Hunter D. Influence of psychological coping on survival and recurrence in people with cancer: systematic review. BMJ 2002,325:1066-75. (9 November.) 2 Watson M, Haviland JS, Greer S, Davidson J, Bliss JM. Influence of psychological response on survival in breas cancer: a population-based cohort study. Lance 1999;354:1331-6. 


\section{Search strategy used is inadequate}

EDITOR-The systematic review by Petticrew et al on the influence of psychological coping on survival in and recurrence of cancer seems comprehensive, but the search strategy used is inadequate. ${ }^{1}$ Searches that rely on keywords in medical databases will miss many important articles. ${ }^{2}$ More can be retrieved by citation searching, but often no alternative exists to hand searching journals.

The end result is that Petticrew et al have identified 26 prospective studies, but we are aware of 12 additional prospective studies in this field (an extra 1425 patients) (references available from us on request). Of course, these studies vary in quality and use different markers of coping (predominantly locus of control measures), but they nevertheless require appraisal in a truly systematic review. The authors have excluded at least 12 non-prospective studies, but retrospective studies can add valuable information to the debate.

Furthermore, we cannot understand why Petticrew et al consider an early assessment of coping style to be a measure of quality, unless it is a proxy for length of follow up. If they had adopted more stringent methodological criteria, as they say, it might have been possible for studies with false negative results to be excluded as much as those with false positive results. Petticrew et al note that only four studies identified over 200 patients, but in fact seven studies have done this. The missing ones are by Funch and Marshall, Holland et al, and Stavraky. ${ }^{3-5}$

It is inappropriate either to force superficial positive thinking or to blame patients for not thinking positively. Methodological rigour is required if research is to contribute to this debate.

Alex Mitchell lecturer in psychiatry

a.j.mitchell@leeds.ac.uk

Manoj Kumar consultant in psycho-oncology and liaison psychiatry

University of Leeds, St James's University Hospital, Leeds LS9 7TH

1 Petticrew M, Bell R, Hunter D. Influence of psychological coping on survival and recanrence in people with cancer: systematic review. BMJ 2002;325:1066-75. (9 November.) 2 Hopewell S, Clarke M, Lusher A, Lefebvre C, Westby M. A comparison of handsearching versus MEDLINE searching to identify reports of randomized controlled trials. Stat Med 2002;21:1625-34.

3 Funch DP, Marshall J. Role of stress, social support and age in survival from breast cancer. J Psychosom Res 1983;27: $77-83$

4 Holland JC, Korzun AH, Tross S, Cella DF, Norton L, Wood W. Psychosocial factors and disease free interval (dfs) in stage II breast cancer. ASCO Proc 5 1986;5:237.

5 Stavraky KM, Donner AP, Kincade JE, Stewart ME. The effect of psychosocial factors on lung cancer mortality at one year.J Clin Epidemiol 1988;41:75-82.

\section{Authors' reply}

EDITOR-Watson et al point out that coping can be measured in different ways. This is why our review included studies using any measure; overall, we found the evidence unconvincing. As regards the importance of helplessness or hopelessness, these studies give little convincing evidence that it significantly influences survival or recurrence. We agree, however, that further good research is needed.
Mitchell and Kumar cannot understand why we consider an early assessment of coping style to be a measure of quality. Yet the early measurement of coping style is a basic criterion for causality: if a factor is postulated to be causal, logically it has to operate before the outcome occurs. Measuring coping style close to diagnosis seems the most appropriate way to assess this factorthe longer after diagnosis, the greater the possibility that coping style may be a result of disease progression, or treatment, rather than an effect. This is also why we included only prospective studies.

Mitchell and Kumar also suggest that we missed 12 studies, but we had in fact seen and excluded most of the studies on their list. These investigated factors such as social support and general wellbeing, while our review addressed coping styles. Two studies initially seemed to be relevant, but one reported insufficient data for inclusion and the other investigated rationality and antiemotionality and so does not seem to be a study of coping. They also imply that our search relied solely on keywords, which it did not. Mitchell and Kumar's claim that we missed a significant portion of the literature is quite simply wrong.

Mark Petticrew associate director

MRC Social and Public Health Sciences Unit Glasgow G12 8RZ

Ruth Bell lecturer

Department of Epidemiology and Public Health, Medical School, University of Newcastle on Tyne, Newcastle on Tyne NE2 4HH

Duncan Hunter assistant professor

Community Health and Epidemiology, Abramsky Hall, Queen's University, Kingston, ON, Canada K7L 3N6

\section{Reconfiguring health systems}

Potential of new ways of using technology needs to be considered

EDITOR-Black is right that health service reconfigurations are dominated by discussions about buildings. ${ }^{1}$ The design and building processes encourage rehousing the existing way of doing things, not creating a better service for patients and clinicians.

Remote consultations are one of the "virtuality and knowledge technologies" whose potential could be missed. They now form an effective, proved part of the service in psychiatry in Australia, ${ }^{2}$ genetics in Wales, and neurology in Northern Ireland. ${ }^{3}$ But the potential to use information and communications technologies to support services will be much greater. Remote monitoring of patients at home can often provide better measurements than those obtainable in the hospitals (however new). ${ }^{4}$ The exacerbation of chronic conditions can be identified early and treatment instituted early, avoiding expensive admission to hospital in chronic heart failure and chronic obstructive pulmonary disease, which both account for a sizeable proportion of emergency medical admissions.

The use of picture archiving and communication systems has focused on hospital radiology. A system serving the whole health community can transform the imaging and reporting services, cut wasted time, and make best use of scarce expertise.

"Store and forward" referrals of patients' history with images and other clinical data for expert opinion will affect the demand for outpatient consultation, ${ }^{5}$ especially when used as part of a redesign of services incorporating general practitioners with a special interest and specialist nurse practitioners. The use of videoconferencing for multidisciplinary meetings is already improving care in psychiatry and in cancer networks, where pathology slides and radiographs can be viewed across multiple geographical sites.

The potential of new ways of using technology should be incorporated in the thinking about service design before too many white elephants are built. This is beginning to be recognised in Wales, Scotland, and Northern Ireland, but barely yet in England.

Ian Jardine management consultant

Modernising Healthcare Partnership, Abingdon, OX14 5LJ

jard43@ntlworld.com

IJ provides consultancy services to the NHS.

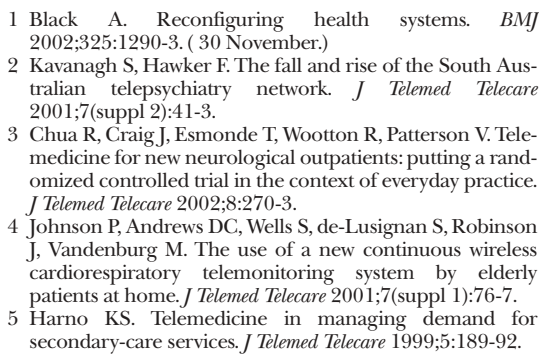

\section{Hospital buildings and increasing} specialisation are here to stay

EDITOR-Complex systems that work, such as healthcare delivery systems, always evolve from pre-existing sytems (often simpler systems) that work. Revolutionary change or design of new complex systems from scratch is seldom successful. Whatever its faults, the NHS works, is used by clients, and meets their needs. The directions of evolutionary change of systems often have multifactorial causes, many of which are seen only in retrospect, if at all. These underlying causes mean that change continues in a virtually unstoppable way for lengthy periods of time.

Specialisation of medical practice is such a phenomenon, associated with a need for large complex hospitals to collocate the specialised services. A newer trend is to try to move services into the home or general practice. The result is that small and medium hospitals are being squeezed out. These trends have continued inexorably for at least 30 or 40 years in every advanced country in the world. The United Kingdom is no exception.

These trends will continue for much longer than currently expected on the basis of logic and foreseeable factors. Increased specialisation is here to stay and will continue apace. Evolution towards fewer but 
larger, more complex hospitals is an inevitable consequence. Movement of technology into the home and general practice will continue. The middle will disappear. If the trends change it will happen as a gradual slowing. There will be no revolution. So, discussion is dominated by buildings because there are often alternative possibilities for the geographic siting of fewer hospitals, and alternatives for which hospitals are squeezed out.

Bruce A Swanson medical administrator

South Australian Department of Human Services, Adelaide, Australia 5083

Bruce.Swanson@dhs.sa.gov.au

1 Black A. Reconfiguring health systems.
2002;325:1290-3. (30 November.)

\section{Effectiveness of trained nurses in preoperative assessment}

\section{Unnecessary ritual should not be continued}

EDITOR-As a trial, the study by Kinley et al shows that trained nurses are (approximately) equivalent to house officers at the tasks of conventional preoperative assessment. ${ }^{1}$ The real question to be asked is why we persist with the ritual of preoperative assessment led by junior staff (of whatever professional discipline) at all.

A decade ago, I and my colleages re-engineered preoperative preparation of patients and developed a system that has eliminated the ritual involvement of junior medical staff altogether. ${ }^{2}$

By using a system led and supervised by a consultant anaesthetist, the tasks of gathering clinical and related information about a patient can be achieved using a combination of methods, including questionnaires, collecting information from general practitioners and other specialists, and selective clinic visits where patients are seen by both nurses and anaesthetists. Thus prepared, patients arrive in hospital two to three hours before surgery, even for major cardiothoracic or vascular surgery. The system has become widespread in most major hospitals in Australia and New Zealand, where hospital practice is broadly similar to that in the United Kingdom.

So why compare nurses to house officers? Surely nurses are better than that.

Ross K Kerridge director, perioperative service John Hunter Hospital, Locked Bag 1, Newcastle Mail Centre, Newcastle, NSW 2310, Australia mdrkk@cc.newcastle.edu.au

1 Kinley H, Czoski-Murray C, George S, McCabe C, Primrose J, Reilly C, et al. Effectiveness of appropriately trained nurses in preoperative assessment: randomised controlled equivalence/non-inferiority trial. $B M J$ 2002;325:1323-6. (7 December.)

2 Kerridge R, Lee A, Latchford E, et al. The perioperative system: a new approach to managing elective surgery. Anaesth Intensive Care 1995;23:591-6.

\section{Paper is missing the point of} preoperative assessment

EDITOR-To wonder who is better at preoperative assessment is to miss the point. ${ }^{1}$ Hospitals now view this as a process to enable surgery, often merely to enable anaesthesia. For many modest procedures this is enough, but for major procedures or those who are unfit it is not. The point of clerking these latter two groups is to introduce the patient to the team who will care for him or her and vice versa. It is to ensure that at least one member of the team has an overall view of the patient and his or her illness so as to care for the patient holistically during what may be a protracted and life threatening illness.

All the changes in perioperative care over the past few years have been away from holistic care towards process driven events. The challenge is not to find who best to do the assessment, but to make it relate and contribute to the whole episode, the illness, and the patient.

The old firm system did this, and it will not come back, but we need to make our new system this good and not merely design it to process patients or, perhaps more accurately, to process waiting lists.

Andrew C Skinner consultant anaesthetist Whiston Hospital, Prescot, Liverpool L35 5DR skinner@summerfld.demon.co.uk

1 Kinley H, Czoski-Murray C, George S, McCabe C, Primrose J, Reilly C, et al. Effectiveness of appropriately rained nurses in preoperative assessment: randomised controlled equivalence/non-inferiority trial $B M J$ 2002;325:1323-6. (7 December.)

\section{Channelling new antidepressants to problem patients may be factor in fatal toxicity}

EDITOR-Buckley and McManus provide a good overview of all reported deaths in the United Kingdom that were suspected to be due to overdosing with antidepressants over the past 15 years compared with prescription rates of the individual drugs. ${ }^{1}$ However, we seriously doubt the validity of their conclusions.

Buckley and McManus assume that the prescription rate is a valid proxy for the frequency of intentional overdosing of the drugs studied. This will not be the case in daily clinical practice. Antidepressant drugs are used for various psychiatric indications, including depressive disorder, anxiety disorder, eating disorder, and obsessive compulsive disorder. Since the risk of taking an overdose as well as the choice of the antidepressant will be related to the underlying disease, confounding by indication will be inevitable.

Channelling of new antidepressants into problem patients has been described before and may be a factor in the high fatal toxicity index found for venlafaxine. In these types of studies the question is did the drug bring the problem to the patient or did the patient bring the problem to the drug?

This question cannot be answered from the data presented in this study, since (severity of) the indication, age and sex of the patients, comorbidity, and comedication all have not been taken into account. The conclusion that treatment with venlafaxine is questionable in patients prone to suicide is in our view therefore unsubstantiated.

Eibert R Heerdink assistant professor

Department of Pharmacoepidemiology, Utrecht University, PO Box 80082, NL-3508 TB Utrecht, Netherlands

e.r.heerdink@pharm.uu.nl

Gerard W K Hugenholtz hospital pharmacis

Altrecht Institute for Mental Health Care,

Dolderseweg 174, 3734 BN Den Dolder,

Netherlands

Welmoed E E Meijer manager, clinical monitoring

Kendle International, Bolognalaan 40, 3584 CJ

Utrecht

Antoine C G Egberts professor of

pharmacoepidemiology

Department Pharmacoepidemiology and

Pharmacotherapy, Utrecht Institute for

Pharmaceutical Sciences, PO Box 80082,3508 TB

Utrecht

Competing interests: ERH and WEEM have done contract research for pharmaceutical companies and the government.

1 Buckley NA, McManus PR. Fatal toxicity of serotoninergic and other antidepressant drugs: analysis of United Kingdom mortality data. BMJ 2002;325:1332-3. (7 December.)

2 Egberts AC, Lenderink AW, de Koning FH, Leufkens HG. Channeling of three newly introduced antidepressants to patients not responding satisfactorily to previous treatment. J Clin Psychopharmacol 1997;17:149-55.

\section{Football may influence when patients see a doctor}

EDITOR-Psychological or emotional stress is often suggested as a cause of disease. In dermatology stress is sometimes cited as a cause of diseases such as psoriasis. The biological causality of such correlations is not always immediately apparent, and stress may have many psychological effects. In chronic diseases it also offers a sense of consolation and explanation, which helps patients cope.

An important source of error seems not to have been taken into account in the study by Carroll et al on football and myocardial infarction. ${ }^{1}$ Delay in seeking medical treatment for myocardial infarction is an important variable. ${ }^{2}$ On the basis of personal experience as a medical house officer in 1986 when Denmark participated in the World Cup finals, I think that simple delay is an important factor in any increased mortality from cardiovascular events at such times.

The emergency rooms were notably empty during all matches, and patients reappeared only some time after the end of any match in which Denmark participated. Undoubtedly a similar pattern was seen in the United Kingdom. National football events apparently have a mesmeric appeal to a large proportion of the male population, and this appeal may keep patients from seeking appropriate medical attention for symptoms that might otherwise have brought them into medical care. Thus, watching football may affect long term health.

Gregor B Jemec consultant dermatologist Division of Dermatology, Department of Medicine, Roskilde Hospital, DK-4000 Roskilde, Denmark ccc2845@vip.cybercity.dk 
1 Caroll D, Ebrahim S, Tilling K, Macleod J, Davey Smith G. Admissions for myocardial infarction and World Cup football: database survey. BMJ 2002;325:1439-42. (21 football: da

2 Schou J. Prehospital emergency medicine. 2nd ed. Amsterdam Harwood, 1997.

\section{Recommendations on syncope and driving must be observed}

EDIToR-Maas et al showed that the adherence of patients with syncope to driving recommendations was poor, despite most patients remembering the advice given by the doctor. ${ }^{1}$ Although the frequency of accidents was shown to be low in this group of patients, the legal position remains that patients should not drive after syncope. The doctor has a duty to inform the patient that driving should cease and the patient has a duty to act on that advice.

The current advice is that after unexplained syncope with high risk of recurrence, a group 1 driver should stop driving for four weeks after the event if the cause has been identified and treated. If no cause is identified, then six months off is required. ${ }^{2}$ When medical conditions likely to affect safe driving persist longer than three months the driver is required to inform the Driver and Vehicle Licensing Agency (DVLA).

Guidance from the DVLA and General Medical Council for doctors is to make sure that patients understand that the condition may impair their ability to drive. ${ }^{2}$ A Canadian court heard how an epileptic driver had a seizure while driving and killed a cyclist. ${ }^{3}$ The driver had not been informed by the two doctors involved in his care that he should not drive. The doctors were held negligent for breach of duty of care and thus liable. An English court could similarly find a doctor negligent, if there had been a failure to tell the patient not to drive in a condition which may endanger the lives of fellow road users.

Patients should be warned that they have a duty to stop driving and inform the DVLA when appropriate. Failure to inform the DVLA is punishable by a fine. Implications for car insurance also arise in the event of an accident. Patients themselves may be held liable for any accident resulting from syncope as any driver holds a duty of care to fellow road users.

Maas et al raised the question of whether their advice was strong enough, and given the poor take-up of the advice I would question this as well. They do not say what advice was given. While the current DVLA medical standards exist, doctors have a duty to ensure that patients are aware of the implications of continuing to drive.

Josie Clare specialist registrar in general and elderly medicine

Leeds General Infirmary, Leeds LS1 3EX

joeandjosie@hospital-doctor.net

I Maas R, Ventura R, Kretzschmar C, Aydin A, Schubert A Syncope, driving recommendations, and clinical reality Syncope, driving recommendations, and clinical
survey of patients. BMJ 2003;326:21. (4 January.)

2 Drivey of patients. BMJ 2003;326:21. (4 January.) Driver and Vehicle Licensing Agency. At a glance guide to
the current medical standards of fitness to drive. Swansea, the current me

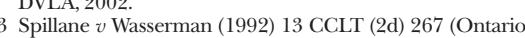
HC).

\section{Patient outcomes and population context affect test accuracy}

EDITOR-Publication of the STARD paper, on standards for reporting of studies of diagnostic accuracy, should ensure increased attention to the problems of poor diagnostic research. ${ }^{1}$ Increased awareness of reporting of accuracy studies should lead to better study designs and hence improve the evidence base for diagnostic tests.

However, accuracy is but one aspect of assessing diagnostic tests. Other evidence is required for determining the clinical utility of a test-reproducibility, effectiveness, and cost effectiveness. A test is not robust if not reproducible, yet evidence is often lacking. The effect of test accuracy on patients' outcomes is crucial, but the size of effect and the optimum balance between sensitivity and specificity depends on the context in which the test is used.

Decisions about patient management may be based on one test alone, as in a screening test, or be part of a battery of tests. For a screening test, in populations with a very low prevalence of disease false negative results are highly undesirable. With additional information about a patient, reducing false positive results may become more important.

Although it may not be possible to provide comprehensive information for established diagnostic tests, thorough appraisal of new tests should include their relation to patient outcomes.

Improved reporting of accuracy studies is an excellent first step since currently new tests can be introduced with little evidence, unlike the rigorous evaluation required for a new drug. However, we should be moving to a staged evaluation for new tests, especially for population screening, that adds evidence of effect on clinical, cost, and personal outcomes to measurement of the basic parameters of sensitivity, specificity, and reproducibility. This demands additional evaluative methods including clinical trials and mathematical modelling beyond the studies discussed by the STARD group.

David Jenkins professor of pathology

david.jenkins@nottingham.ac.uk

Elaine Bentley academic epidemiologist

School of Clinical Laboratory Sciences, University of Nottingham, Queen's Medical Centre, Nottingham NG7 2UH

1 Bossuyt PM, Reitsma JB, Bruhns DE, Gatsonis CA, Glasziou PP, Irwig LM, et al. Towards complete an accurate reporting on studies of diagnostic accuracy: the STARD initiative. BMJ 2002;325:41-44. (4 January.)

\section{Mind and body split}

Philosophy can be detrimental to doctors

EDITOR-Bracken and Thomas raise the old chestnut of the Cartesian mind-body split and offer some formidable names (such as Wittgenstein and Heidegger) to address it. However, their suggestion that patients would benefit if more doctors studied the philosophy of mind is neither appealing nor evidence based.

Unfortunately the histories of psychiatry, philosophy, and politics are alike in that they have been dominated by radical intellectuals. The contribution of many of these has been largely to sow confusion and conflict. It is all too easy to believe that these intimidating authorities and their followers give weight to one's own views and justify preaching one's own prejudices. Bracken and Thomas are prone to this fault-they are the self proclaimed gurus of British "postpsychiatry," named to imply that they have moved on from "antipsychiatry." Now they claim to have moved on from the mindbody split.

If Bracken and Thomas followed more helpful philosophers perhaps they would know that, just like many of the other problems to which they offer solutions, this was not a real problem in the first place. Gilbert Ryle's famous phrase "the Ghost in the Machine" was an attack not just on Cartesian dualism but on philosophising about the mind in general. ${ }^{3}$ One of the Oxford "ordinary language" school, he showed in helpful, detailed examples that intelligent consideration of what people actually do and say, think and feel is productive whereas mental philosophy is not. He advised that we not consider a man as a machine-with or without a ghostly mind-but as an animal, in fact a higher mammal-namely, man.

I contend that human physical and social biology are far more relevant areas of study for doctors than philosophy. Reading the content of postpsychiatry leads me to consider that study of philosophy (and politics) may be detrimental to doctors, and therefore to patients. Perhaps the $B M$ J should run a campaign against it.

Philip A Sugarman medical director St Andrew's Hospital, Northampton NN1 5DG psugarman@standrew.co.uk

\section{Bracken P, Thomas P. Time to move beyond the mind-body split. BMJ 2002;325:1433-4 (21 December.) 2 Bracken P. Thomas P. Postpsychiatry: a new direction for 2 Bracken P, Thomas P. Postpsychiat
mental health. BMJ 2001;322:724-7. \\ Ryle G. The concet of wind. London: Oxford Unive sity Press, 1949.}

\section{Medical professionals in Asia have} subscribed to Western thought

EDITOR-Bracken and Thomas's editorial on moving beyond the mind-body split is timely and thought provoking, although it focuses on Western philosophical thought and all but ignores other traditions of knowledge.

While Western thought haggled over the split between body and mind, Eastern traditions such as Ayurveda (with its lineage to Vedic systems of knowledge in India) emphasised the interaction between the two. For example, the classical Indian texts of Susrutha and Charaka (200 BC-AD 400) describe the interaction of the body and mind in the causation of disease. ${ }^{2}$ Buddhist philosophy (c.600 BC) too takes a similar view and describes the mind and body as 
neither separate nor identical and not even alternatives, but inseparable, like two bundles of reeds, supporting each other. ${ }^{9}$

However, distinct differences are obvious even in this rich Eastern tradition of knowledge. The Vedic systems describe a distinct soul in addition to the mind-body continuum, which I see as similar to res cogitans of Descartes.

The Buddhist view on the other hand lacks an immutable soul and is closer to the ideas expressed in the editorial. Reality is stated to be a construct (using information arising from the sense organs), which gives an illusion of an identifiable self. ${ }^{4}$ This self is in effect a stream of cognitions, a series of successive mental and bodily processes which are impermanent. ${ }^{4}$ Experiencing and gaining insight of this "reality of the illusion" and pathways to liberate from the illusion are given primacy.

These Eastern models of reality could result in a paradigm shift in most of us, who are otherwise conceptually locked in to a dualistic model of reality. These in turn could encourage people to explore new psychologies based on meditation, mindfulness, and imagery techniques.. Unfortunately, we Western oriented medical professionals (including psychiatrists) living in Asian countries have not tapped into our own indigenous systems of knowledge and have instead embraced Cartesian dualism (and the culture that goes with it) lock, stock, and barrel.

Saroj Jayasinghe associate professor
Faculty of Medicine University of Colombo,

Faculty of Medicine Un
Colombo 08, Sri Lanka

saroj@sri.lanka.net

1 Bracken P, Thomas P. Time to move beyond the mind-body split. BMJ 2002,325:1433-4 (21 December.)

2 Ramachandra Rao SK. Mental health in Ayurveda: source book of Charaka and Susrutha samhita. National Institute of Mental Health and Neuro Sciences. Bangalore: NIMHANS Publications, 1990.

Goonatilake S. Towards a global science. New Delhi: Vistaar Publications, 1998.

Bodhi B. The great discourse on causation: the Mahanidana Sutta and its commentaries. Kandy: Buddhist Publication Society, 1995.

\section{Evidence b(i)ased medicine}

\section{CRAP may be sounding timely alarm}

EDITOR-Is the move complete from the early idealistic vision of evidence based medicine (EBM) to the earthly establishment of evidence biased medicine, complete with priests, liturgy, and inquisition? I think not, at least not yet. But the Clinicians for the Restoration of Autonomous Practice (CRAP)'s fortuitous uncovering of evidence based medicine's religious tracts in the making sounds a none too early alarm. ${ }^{1}$ Practitioners who idealistically continue to apply available evidence to medicine will increasingly have to fear the wrath of the zealots when they resort to that most lay of clinical approaches: common sense.

Prompted by your revelations, I discovered more of evidence based medicine's dire consequences by opening the website of a regulatory agency and then playing the compact disc of an approved evidence based medicine textbook in html.

Firstly, only corporations that can afford to punt $\$ 1$ bn per shot and then wait around 10-12 years to reap the benefits, if any, are allowed to develop new treatments.

Secondly, new potential indications of older drugs are not worth exploring. A new patent will last only three years and nobody will invest for everybody else to grab the benefits.

Thirdly, the same is true for "traditional medicine." We all sneer at it, idealists and zealots alike, precisely because of the lack of evidence, but the costs of an evidence based approach to prove the worth, if any, of a specific remedy will never be met.

On top of failing to provide evidence that it does more good than harm, evidence based medicine may actually be stifling medical progress, in cahoots with regulators (and class action suitors). That the number of new treatments available to patients has declined considerably in recent years may be due to a cyclical pattern but could also result from the huge deterrent that current regulations impose on proponents. Whether evidence based medicine will implode, as CRAP suggests, only time can tell. If that time is nearing, however, will Samson take down the temple with all the Philistines?

Massimo Porta associate professor of medicine Department of Internal Medicine, University of Turin, Corso AM Dogliotti 14, I-10126 Turin, Italy massimo.porta@unito.it

Competing interests: None declared.

1 Clinicians for the Restoration of Autonomous Practice (CRAP) Writing Group. EBM: unmasking the ugly truth BMJ 2002;325:1496-8. (21 December.)

\section{CRAP should now consider the role of} common sense

EDITOR-I am a simple, EBM-challenged, orthopaedic surgeon. (Is this reiteratively redundant?) I have a question that may get to the heart of the problem that the Clinicians for the Restoration of Autonomous Practice (CRAP) has so eloquently uncovered.

During the course of practising orthopaedic surgery (although not documented in the literature), it has been my experience (those of you who adhere to the EBM doctrines will, I hope, excuse this phraseology) that when I hit my finger with a hammer (or mallet, for that matter) my finger hurts. It is even worse if I use a power tool (as in drilling through the finger). My question: how many times do I have to do this before I can say that I have sufficient evidence to potentially causally link the hammer blow to my finger hurting? And what do I use as the control?

One of my teachers in medical school once noted that disciplines such as orthopaedic surgery were very difficult for some physicians to master because they required the exercise of common sense. Is the inability to use common sense (CS) what lies behind the development of EBM? Perhaps it is an attempt by the CS-challenged among us to make the CS-gifted feel bad (or just inadequate). I think this is an area of research that CRAP might find fruitful as it continues its investigations into this new religion.

James Michelson professor, orthopaedic surgery George Washington University, Washington, DC 20037, USA msdjdm@gwumc.edu

Competing interests: JM likes hammers and power tools. 1 Clinicians for the Restoration of Autonomous Practice
(CRAP) Writing Group. EBM: unmasking the ugly truth. BMJ 2002;325:1496-8. (21 December.)

\section{CRAP is on the right track}

EDITOR-How and where can I join or subscribe to CRAP?

Perhaps I was mistaken, but when evidence based medicine was first translated to the United States, it seemed like the translation of the Bible into English. It was taking the research community and putting the results into the hands of the common doctor. We might not have the time with every patient, but with training any doctor could look at the evidence and understand how we came to a conclusion or a treatment, or understand that there was no hard evidence, just clinical practice. It was populism. It was wonderful, and those who came to understand it felt like missionaries spreading the word to all. You can do it too.

However, now it has become a dogma. Unless the Cochrane Collaboration or the Agency for Health Care Policy and Research (AHCRP) have made a recommendation or review, the conclusion or research or practice is not "evidence based." Books are called "well researched" but they are not evidence based unless they spout the conclusions of a very small number of organisations whose members we glimpse only vaguely. And the number of organisations is shrinking. Soon we will have to practise medicine on the basis of a few precepts.

So how can I join CRAP? Or is it going underground, like Christianity into the Roman crypts?

Jo Ann Rosenfeld assistant professor, Johns Hopkins University

1112 Nicodemus Road, Reisterstown, MD 21136 USA

jrosen0125@aol.com 1 Clinicians for the Restoration of Autonomous Practice
(CRAP) Writing Group. EBM: unmasking the ugly truth. BMJ 2002;325:1496-8. (21 December.)

\section{bmj.com}

Letters appearing here are an edited selection of rapid responses originally posted on bmj.com

We ask for all letters to the editor to be submitted as rapid responses via bmj.com

For advice see: bmi.com/rapidresponses 